Lionel March
Martin Centre for Architectural
and Urban Studies
University of Cambridge
$1-5$ Scroope Terrace
Cambridge, CB2 1PX, UK
lmarch@ucla.edu
Keywords: Andrea Palladio,
arithmetic mean, geometric
mean, harmonic mean, number
symbolism, Vitruvius, Alberti,
triangular numbers, rational
approximations

\title{
Research \\ Palladio, Pythagoreanism and Renaissance Mathematics
}

Abstract. This paper examines the proportional qualities of Palazzo Antonini in terms of contemporary, Renaissance mathematics. It reveals that Palladio was either a masterful arithmetician, or a serendipitous genius.

Mathematical studies of Palladio's work are most often written from a modern view point. One serious anachronism is the use of the decimal notation. The problem here is that the decimals were not introduced until Simon Stevin published his arithmetic in 1585 . Conversion of ratios into decimals obfuscates the rational number system employed in Palladio's time. Today, a rational number is represented by $p / q$ where numerator and denominator are whole numbers.

Numbers were conceived with a rich variety of character unfamiliar to many commentators today. Modern writers are more aware of powers and roots, but less of polygonal and pyramidal numbers, less of numbers as lines, oblongs, beams, bricks and scalenes; more of arithmetic, geometric and harmonic means, but less of the seven to eight other classical means known to Renaissance arithmeticians; more of odd and even numbers, but less of the finer classifications current in Palladio's period; less of the tenfold description of rational numbers; and less of alphanumeric equivalences, encodings and cabalistic manipulations.

Suppose a contemporary of Palladio, (1508-1580) such as Girolamo Cardano (15011576), were to have examined the Quattro libri dell'architettura [Palladio 1570; Tavernor and Schofield 1997] from an arithmetical viewpoint. Cardano is cited in Barbaro's commentaries on Vitruvius [1556; 1567], and Cardano confirms this citation in The Book of My Life [Grafton 2002]. In this autobiography, Cardano writes that he was taught arithmetic by his father. From his own description it can be assumed that what he learned as a child would have been a blend of practical abachista computations and arcane, Pythagorean arithmetic - Nicomachus and/or Boethius. He mastered Euclid (Books I - VI) at the age of twelve. A polymath, he was a prolific author on mathematics, astrology, medicine, publishing his algebraic masterwork Ars Magna in 1570, the year also of the Quattro libri. This paper looks selectively at the Quattro libri through the lens of such a contemporary.

On the title page Book I sets out "rules [avertimento] essential to building" [Tavernor and Scholfield 1997: 1]. In chapter 21, Palladio numerates seven room shapes "that are most beautiful and well proportioned", of which, aside from the circle, six are rectangular: "the square; or their length will equal the diagonal of the square of the breadth; or a square and a third; or a square and a half; or a square and two thirds; or two squares" [Tavernor

Nexus Network Journal 10 (2008) 227-244

NEXUS NETWORK JOURNAL - VOL. 10, NO. 2, 2008227

1590-5896/08/020227-18 DOI 10.1007/ s00004-007-0067-5

(C) 2008 Kim Williams Books, Turin 
and Schofield 1997: 57]. A Renaissance arithmetician, particularly a player of rithmomachia like Cardano [March 1998: 49ff], would instantly identify these ratios with successive pairs of triangular numbers (fig. 1):
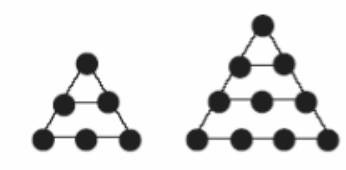

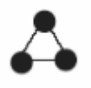
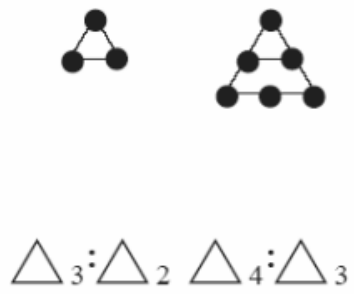

2: 1

$5: 3$
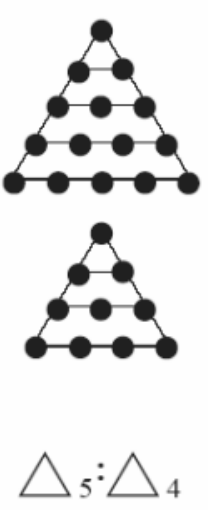

$3: 2$
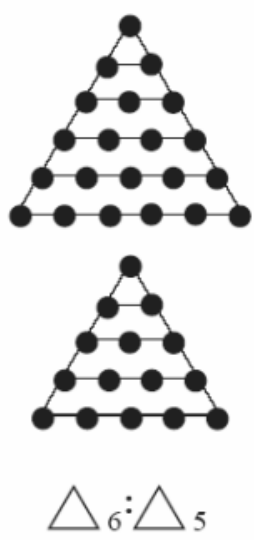

$7: 5$
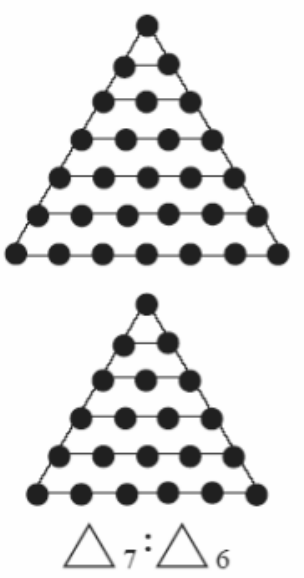

$4: 3$

Fig. 1. Ratios between successive pairs of triangular numbers:

$6: 3:: 2: 1 ; 10: 6:: 5: 3 ; 15: 10:: 3: 2 ; 21: 15:: 7: 5 ; 28: 21:: 4: 3$

The ratio $7: 5$ is a classic proxy for $\sqrt{ } 2: 1$. Sir Thomas Heath notes that "Plato, and even Pythagoreans, were familiar with $7 / 5$ as an approximation for $\sqrt{ } 2$ " [1986, II: 119]. Alberti in Ludi Matematici comments, in reference to Pythagoras's theorem, that people who make a right-angled triangle from two sides of five feet and a hypotenuse of seven "are wrong, because their squares do not respond to the total; but ignore one fiftieth part" [Rinaldi 1980: 52]. By Pythagoras's theorem:

$$
5^{2}+5^{2}=50>49=7^{2} \text {. }
$$

There is no rational number which represents $\sqrt{2}$. It is said to be irrational, inexpressible. Inexpressible roots can be approximated using a well known relation between the classic means: arithmetic mean > geometric mean > harmonic mean, which when applied to rational extremes $\mathrm{p}>\mathrm{q}$, yields

$$
(p+q) / 2>\sqrt{ } p q>2 p q /(p+q) .
$$

Thus between $p=2$ and $q=1$

$$
3 / 2>\sqrt{ } 2>4 / 3 .
$$

Now, a value between $3 / 2$ and $4 / 3$ was known to be $(3+4) /(2+3)=7 / 5$, or the sum of the numerators over the sum of the denominators [Chuquet 1484; see Flegg et al. 1985].

In searching for a rational proxy for $\sqrt{2}$, it is seen that two other numbers $3 / 2$ and $4 / 3$ are implicated. Thus, three of Palladio's proportions are evoked with two more marked by extremes $2 / 1$ and $1 / 1$. Only the ratio $5: 3$ is not evoked. However, $5 / 3$ is the contraharmonic mean between 2 and 1 , as is illustrated in Nicomachus's Introduction to 
Arithmetic (II.28) as $6: 5: 3$, or $2: 5 / 3: 1$. This is the fourth mean defined among ten cited by Nicomachus [D’Ooge 1938]. Any competent Renaissance arithmetician would be familiar with this mean.

Turn now to Book II, which "contains drawings of many houses designed by him [Palladio]". In Chapter 1 Palladio declares that "in the previous book I explained everything that seemed most worthy of attention in the construction of public buildings and private houses so that the resulting work may be beautiful, graceful, and permanent ..." [Tavernor and Schofield 1997: 77]. The first scheme illustrated, Chapter 3, is Palazzo Antonini in Udine (fig. 2). It might be expected that this scheme would be an exemplar of the 'rules' set out in the first book. A cursory glance, however, shows that only the corner rooms on the garden side fit the canon. They are square, $17: 17:: 1: 1$, the ratio of equality.

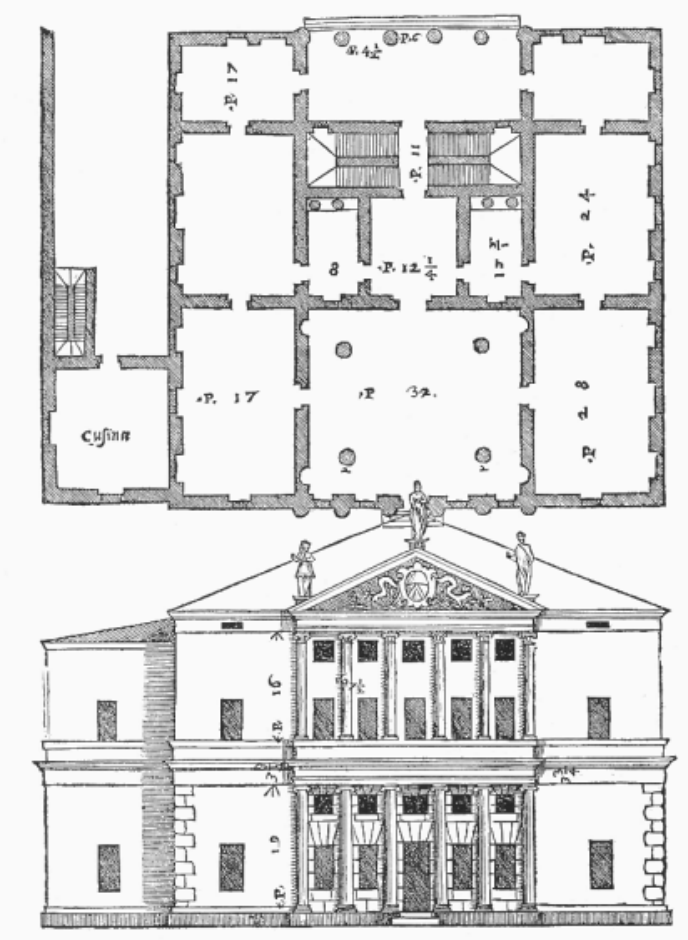

Fig. 2. Woodcut of the Palazzo Antonio from Palladio's Quattro libri [Tavernor and Schofield 1997: Bk. II, ch. III (p. 80)]

Looking at the wood cut showing plan and street elevation, a Renaissance arithmetician would take particular interest in the numbers. There are fourteen distinct numbers on the plate measuring dimensions in Vicentine feet. In no way do these numbers make it possible to compute the overall dimensions of the scheme. Notably absent are the thicknesses of the walls. It suggests that the numbers are independent of material, that is, they tend towards the Pythagorean 'conceptual and immaterial' . They relate to empty space, not solid matter. Someone familiar with Nicomachus might recall his words: 
All that has by nature with systematic method been arranged in the universe seems both in part and as a whole to have been determined and ordered in accordance with number, by the forethought and the mind of him that created all things; for the pattern was fixed, like a preliminary sketch, by the domination of number pre-existent in the mind of the world-creating God, number conceptual only and immaterial in every way, but at the same time the true and the eternal essence, so that with reference to it, as to an artistic plan, should be created all [things] (Book I.6).

Nicomachus (II.19), with number in mind as source of creation, reports that:

... things are made up of warring and opposite elements and have in all likelihood taken on harmony - and harmony always arises from opposites; for harmony is the unification of the diverse and the reconciliation of the contrary-minded ....

In this spirit, Johann Reuchlin had written early in 1516 that:

... [the] world is more perfect, the more it contains many modes of numbering: equality, inequality; squares, cubes; length and area; primes or compound numbers [M \& S Goodman, 1983].

An examination of the Antonini woodcut reveals many modes of numbering appreciated by a Renaissance arithmetician. Fig. 3 shows the numbers reduced to their factors. Prime numbers are depicted as one dimensional lines, since 1 is their sole factor aside from the prime itself. Numbers with two factors greater than 1 are depicted as two dimensional oblongs. Square numbers are depicted as squares. Oblongs with sides in the relation $p+1: p$ are given the special name heteromecic. With more than three factors greater than 1, three dimensional depictions are possible. Three distinct factors produce a 'scalene' solid. Two equal factors each less than the third produces a 'beam'; or each greater than the third, a 'brick'. If all three are equal, the cube is produced. More than three factors lead to multiple representations of the number. All Antonini numbers are generated by the following factors $2,3,5,7,11,17,19$. In the Renaissance all primes were considered to be odd. The dyad, 2, held a special position as 'the other' to the monad, 1, 'the same'. It will be noted that 13 is missing in the sequence of primes from 3 to 19 . In the woodcut the dimension $1 \& 71 / 2$ is inscribed on a second floor column. This dimension is in feet and inches and may be converted to $15 / 8$, or $13 / 8$ feet. The sequence of odd primes is thus complete. (The number 13 was not included in the original Antonini set, fig. 3, because it had to be computed from the one measure in fig. 2 to use Vincentine inches.) The span of odd numbers in the augmented Antonini set ranges from 3 to 19. Barbaro, in his commentary on Vitruvius, reminds the Renaissance reader that $3+5=8=2^{3} ; 7+9+11=$ $27=3^{3} ; 13+15+17+19=64=4^{3}$, and that $1^{3}+2^{3}+3^{3}+4^{3}=100=10^{2}$, a relationship remarked upon by Alberti (IX.5). It may not be a coincidence that the pair of small central rooms in the Palazzo each has an area of 100 square feet.

Other modes of numbering are illustrated in fig. 4. For Palladio and his numerate contemporaries, numbers were 'perfect' or not. In the Vitruvian tradition, 6 and 28 were known to be perfect since $6=1 \cdot 2 \cdot 3$ and $1+2+3=6$; while $28=1 \cdot 2 \cdot 2 \cdot 7$ and $1+2+4+7$ $+14=28$. Numbers which are not perfect are classified as 'abundant' or 'deficient' depending on whether the sum of factors exceeds or falls short of the number.

230 LiOnel MARCH - Palladio, Pythagoreanism and Renaissance Mathematics 


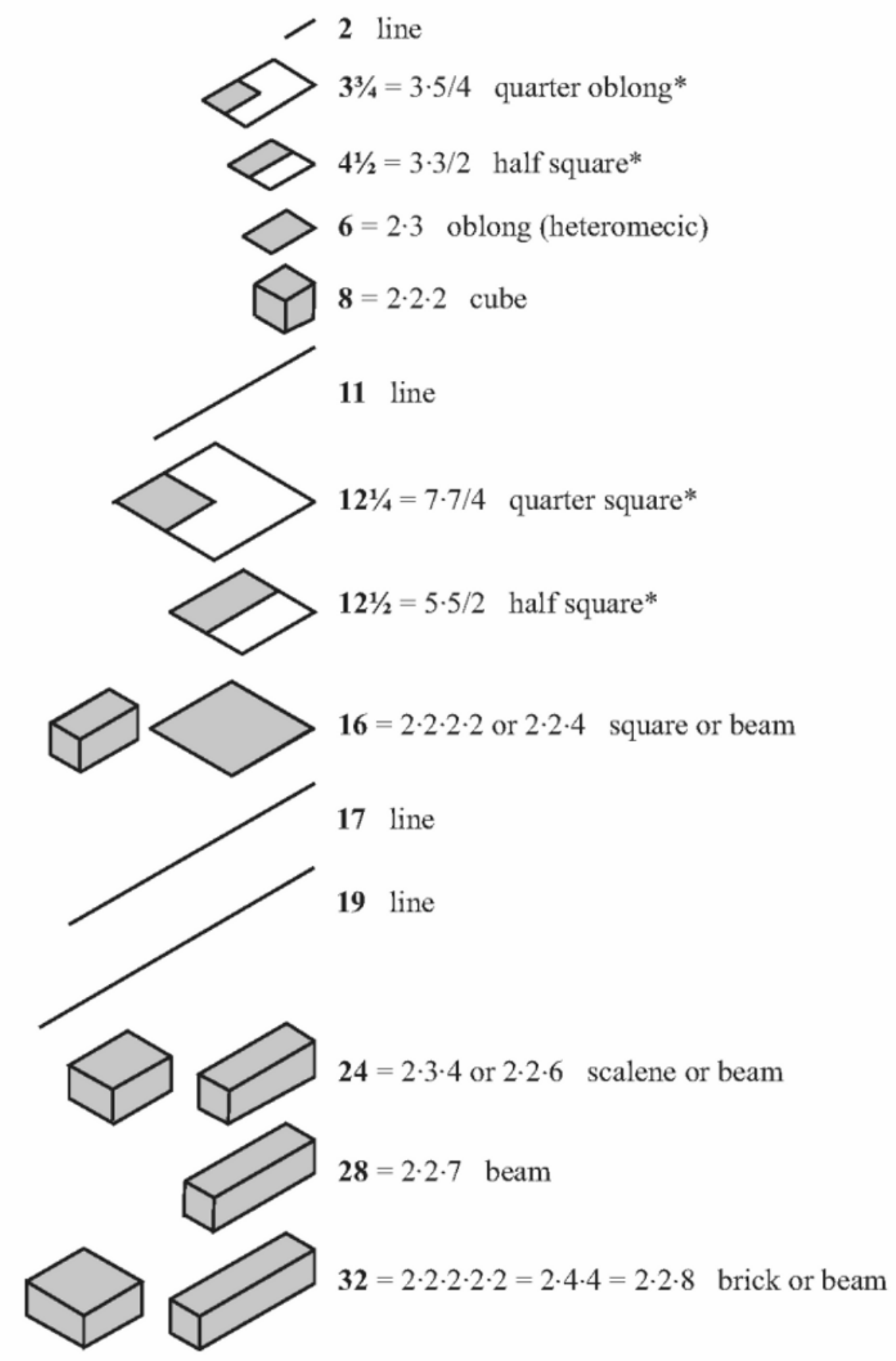

Fig. 3. The Antonini number set as conceived by Renaissance arithmeticians depicting, in isometric projection, factors as lines, oblongs and solids (Nicomachus II.15-17). Numbers marked ${ }^{*}$ are presented as improper fractions 
Even numbers were divided into three distinct classes: even-even, which today would be described as positive powers of $2(2,4,8,16,32, \ldots)$; even-odd, which when halved give an odd number $(6,10,14,18,22, \ldots)$; and odd-even, in which halving leaves an even number $(12,20,24,28,36, \ldots)$. Odd numbers were either prime $(3,5,7,11,13,17,19$, $\ldots$ ), or composite $(9,15,21,25,27,35, \ldots)$. Then again, numbers were visualized as polygonal. Triangular numbers are illustrated above in fig. 1 . Square numbers may be seen in the same way, as can cube numbers in three dimensions.

\begin{tabular}{|c|c|c|c|c|}
\hline 2 & & & & prime* \\
\hline $33 / 4 \rightarrow 15$ & $1+3+5=9$ & deficient & $3 \cdot 5$ & odd-composite \\
\hline $4^{1 / 2} \rightarrow 9$ & $1+3=4$ & deficient & $3 \cdot 3$ & odd-composite \\
\hline 6 & $1+2+3=6$ & perfect & $2 \cdot 3$ & even-odd \\
\hline 8 & $1+2+4=7$ & deficient & $2 \cdot 2 \cdot 2$ & even-even \\
\hline 11 & & & & prime \\
\hline $12^{1 / 4} \rightarrow 49$ & $1+7=8$ & deficient & $7 \cdot 7$ & odd-composite \\
\hline $12^{1 / 2} \rightarrow 25$ & $1+5=6$ & deficient & $5 \cdot 5$ & odd-composite \\
\hline 16 & $1+2+4+8=15$ & deficient & $2 \cdot 2 \cdot 2 \cdot 2$ & even-even \\
\hline 17 & & & & prime \\
\hline 19 & & & & prime \\
\hline 24 & $1+2+3+4+6+8+12=36$ & abundant & $2 \cdot 2 \cdot 2 \cdot 3$ & odd-even \\
\hline 28 & $1+2+4+7+14=28$ & perfect & $2 \cdot 2 \cdot 7$ & odd-even \\
\hline 32 & $1+2+4+8+16=31$ & deficient & $2 \cdot 2 \cdot 2 \cdot 2 \cdot 2$ & even-even \\
\hline
\end{tabular}

Fig. 4. Further Renaissance classification of the Antonini number set. The first column after the numbers in bold shows the sums of divisors by which numbers are said to be deficient - sum less than the number, abundant - sum greater than number, or perfect - sum equal to number. Note the presence of two perfect numbers, 6 and 28. The next perfect number is 496. Vitruvius cites these. There then follows a column of factors and a classification into even and odd number types (Nicomachus II.8 - 13). The final column shows those numbers which are either triangular or square.

* The even number 2 had a special place as the dyad and was rarely ranked with the other primes all of which are odd 
Once the Renaissance classifications are appreciated, the Antonini set is seen to satisfy the Nicomachean requirement, in harmonious 'world-making', for contrariness and diversity among its members; and Reuchlin's Pythagorean ingredient for perfection in its many modes of numbering. Pre-existent numbering ensures both harmony and perfection in creative activity.

\begin{tabular}{|c|c|c|c|c|c|c|c|c|c|c|c|c|c|c|}
\hline I & & $33 / 4$ & & & 8 & & $12 \frac{1}{4}$ & & & & & & & \\
\hline I & & & & 6 & & 11 & & & 16 & & & & & \\
\hline I & & & & 6 & & & & & & 17 & & & 28 & \\
\hline I & & & & 6 & & & & & & & 19 & & & 32 \\
\hline I & & & & & & & & & 16 & & & 24 & & 32 \\
\hline I & & & & & & & & & & & & 24 & 28 & 32 \\
\hline II & 2 & & & & 8 & & & & & & & & & 32 \\
\hline II & & & $41 / 2$ & 6 & 8 & & & & & & & & & \\
\hline II & & & & & 8 & & & & 16 & & & & & 32 \\
\hline $\mathrm{X}$ & 2 & & & 6 & 8 & & & & & & & & & \\
\hline $\mathrm{X}$ & 2 & & & & & & & & & 17 & 19 & & & \\
\hline X & & $33 / 4$ & & & & & $12^{1 / 4}$ & & 16 & & & & & \\
\hline $\mathrm{X}$ & & & $41 / 2$ & & & & & $12^{1 / 2}$ & & 17 & & & & \\
\hline $\mathrm{X}$ & & & & 6 & & 11 & & & & 17 & & & & \\
\hline $\mathrm{X}$ & & & & & 8 & 11 & & & & & 19 & & & \\
\hline $\mathrm{X}$ & & & & & 8 & & & & & & & 24 & & 32 \\
\hline $\mathrm{X}$ & & & & & & 11 & & & & 17 & & & 28 & \\
\hline & 2 & $3 \frac{3}{4}$ & $41 / 2$ & 6 & 8 & 11 & $12 \frac{1}{4}$ & $12^{1 / 2}$ & 16 & 17 & 19 & 24 & 28 & 32 \\
\hline
\end{tabular}

Table 1. Proportionate relations between numbers span the Antonini set. Three Nicomachean means are noted: I, arithmetic; II, geometric; and X, the tenth mean in which $b=a-c(a>b>c)$

A study of the Antonini set also shows that the numbers are related proportionately in terms of the Nicomachean means (Table 1). Every number is related to at least two other and in some case several pairs. The relationships 'span' the set from 2 to 32 . The simple Nicomachean tenth mean, $X$, is easily found in the set although it is not usually identified as such in modern studies. It does appear in Fibonacci references since its terms $a>b>c$ satisfy $a=b+c$, the condition between three consecutive terms of a Fibonacci sequence. 
However, in determining convergents to the extreme and mean ratio, this relationship was not recorded explicitly until Kepler in the seventeenth century [Herz-Fischler 1998].

Returning to the plan, the spatial arrangement of the numbers in the wood cut may be examined (fig. 5). The ratios are oriented (left to right I front to back). They are classified in the contemporary manner [Belli 1573; Wassell and Williams 2003] showing yet more diversity and contrasts among the numbers of the Antonini set. As has been observed, only the square corner rooms $(1: 1)$ precisely match the seven canonic proportions. The garden loggia is assumed to be 32 : 17, but Palladio avoids dimensioning it. In any event, it is technically not a room [sala]. There are two rooms at the centre of the sides of the building (24: 17). Earlier it was demonstrated that

$$
3 / 2>\sqrt{ } 2>4 / 3 \text {. }
$$

Taking $3 / 2$ and $4 / 3$ as new extremes, another iteration of this same procedure gives improved convergents $17 / 12>\sqrt{ } 2>24 / 17$.

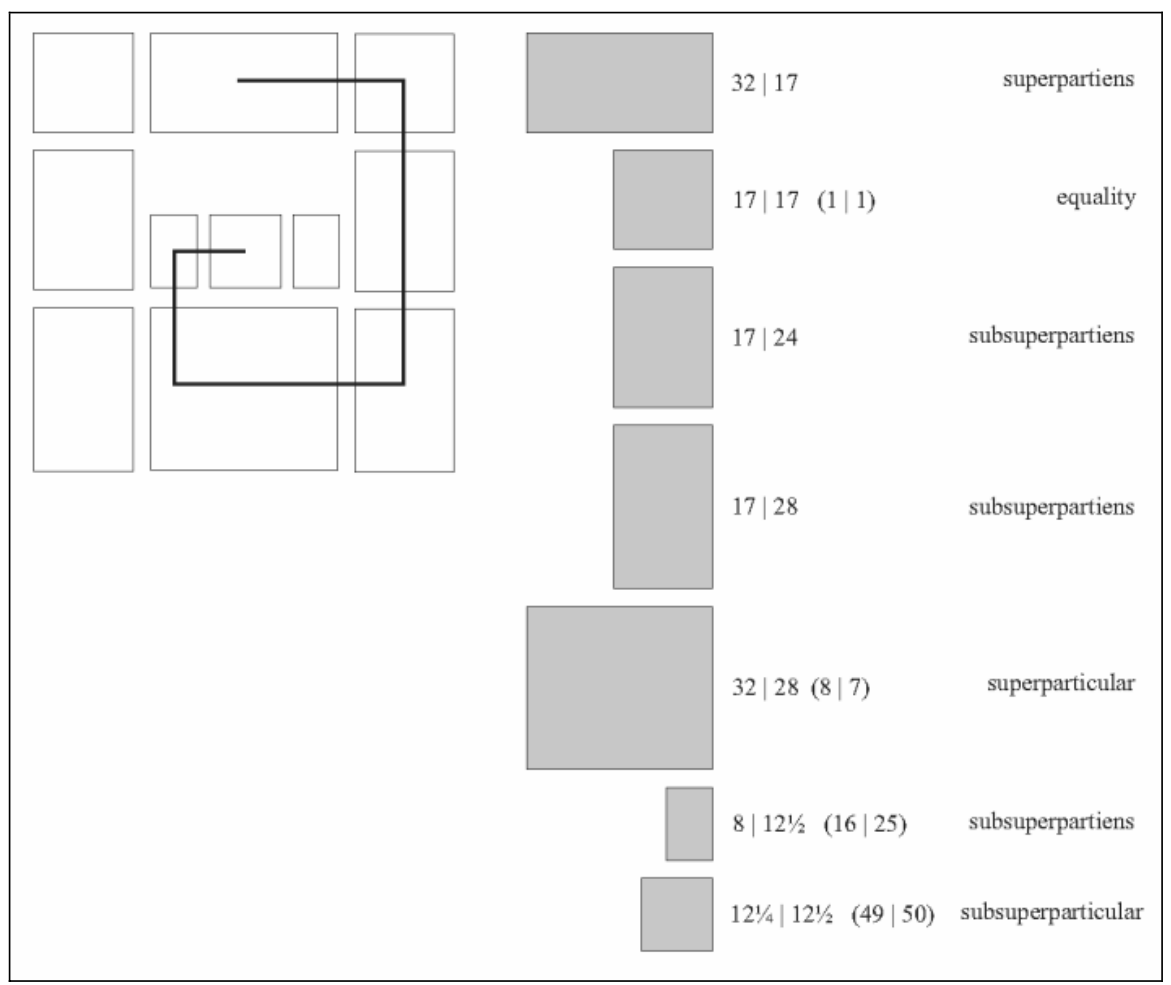

Fig. 5. Schematic of the Palazzo Antonini plan showing room dimensions in Vicentine feet. The ratios are oriented (left to right I front to back) and described in the contemporary manner. The first 'room' is the garden loggia and its dimensions are extrapolated from the principal hall $(32 \mid 28)$ on the street side and the two side rooms, left and right, (17| 17) 
Thus these two side rooms conform, as rational proxy $24: 17$, to the canonic $\sqrt{ } 2: 1$. On the street, the two corner rooms are $28: 17$. The dimension of 28 evokes perfection, but its relation to the width 17 is not obvious. If Palladio had intended a room of proportion $5: 3$ of width 17 , he would have computed its length as $17 \cdot 5 / 3=281 / 3$. Thus, for a room of width 17, a $5: 3$ room has a length of 28 to the nearest foot. This can be viewed as a sensible, practical adjustment.

The main hall is $32: 28:: 8: 7$. Like $7 / 5$ for $\sqrt{ } 2,7 / 4$ had traditionally been regarded as a rational proxy for $\sqrt{3}$. This implies a right angled triangle of sides 7 and 4 . The sum of the squares is $49+16=65$. Now $\sqrt{65}-$ the hypotenuse - is close to $\sqrt{64}=8$ in the same way that $\sqrt{50}$ is close to $\sqrt{ } 49$ (as in the analysis of $7: 5$ above). The ratio $8: 7$ is then seen to be the ratio of the side of an equilateral triangle to its altitude. But this ratio, geometrically, is precisely $\sqrt{ } 4: \sqrt{3}$. Thus since $8: 7$ is a rational proxy for $\sqrt{ } 4: \sqrt{3}$, the canonic ratio $4: 3$ appears in the guise of its roots, radices.

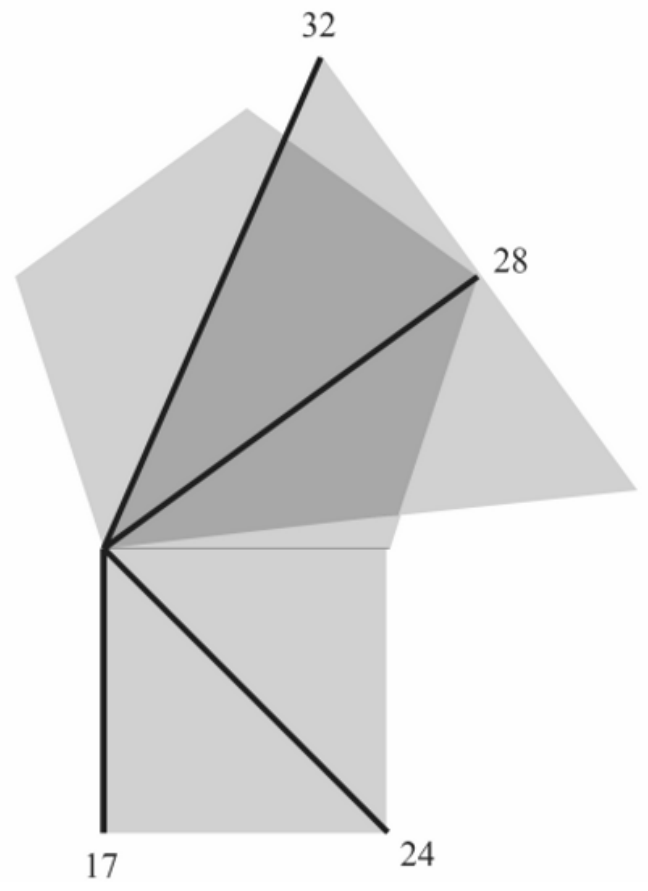

Fig. 6. Arithmo-geometric relations between the main room dimensions. Within tolerance, a square of sides 17 has a diagonal of 24, a regular pentagon with side 17 has a chord of length 28 , and an equilateral triangle of altitude 28 has sides of length 32

There is a pair of small rooms whose proportion is $25: 16:: 5^{2}: 4^{2}$. If these were intended to be $4: 3$ rooms, then with a width of 8 , their length would be $8 \cdot 3 / 2=12$. Yet Palladio adds a half foot in length. More likely, the architect evokes Alberti's innatae correspondentae (IX.6), those natural correspondences relating to geometrical figures. In this case, squares on the sides of the iconic 3, 4, 5 Pythagorean right angled triangle come to the potentiae $9,16,25$. Note that the intercolumniation of the hexastyle portico is $9 / 2$, which with $16 / 2=8$, and $25 / 2$, the sides of the central room, completes this Pythagorean 
triple at half scale. That Palladio does not accept the dimension 12 for a room of width 8 shows that his practice deliberately ranges beyond the canon.

The central, inner room has the ratio $50: 49$. As Alberti had observed this ratio is onefiftieth short of the equality. Why does Palladio not make this central room a precise square? Perhaps Palladio hints at his interest in computations such as those related to roots, and $\sqrt{2}$ in particular. This central room can thus be seen as an 'ancestor', by virtue of computation, to the two central side rooms.

In Architectonics of Humanism [March 1998: 267] I draw attention to relationships between the areas of rooms in the case of Villa Malcontenta. Ratios between room areas in Palazzo Antonini reveal further evidence of Palladio's computational skills. Between the garden side corner rooms and the central rooms at each side, the ratio of areas is $24: 17$, or $\sqrt{2}: 1$. The ratio between the areas of these central side rooms and the street side corner rooms is $28: 24$, or $7: 6$. The ratio of areas between these side rooms and the central hall is 32 : 17 which would appear to be the proportion of the garden loggia. Hidden in this dimension is the ratio $17: 16$, familiar at the time as a semitone used in tuning a lute. Two $17: 16$ rectangles long-side by long-side produces one that is $32: 17$.

Barbaro, with whom Palladio collaborated in his commentaries on Vitruvius, derives ratios through 'addition' and 'subtraction'. These procedures are equivalent to modern multiplication and division. Perhaps $32: 17$ is arrived at through such procedures. For example, the 'addition'

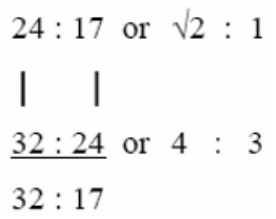

clearly shows a relationship between two canonic ratios.

The ratio $28: 17$ bears examination in the same way:

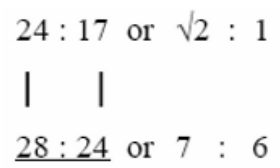

$28: 17$

Now $7: 6$ is derived from the procedure using the inequality between the three classic means in determining a rational convergent for $\sqrt{4}: \sqrt{3}$ :

$$
(1+4 / 3) / 2>\sqrt{ } 4: \sqrt{ } 3>2.1 .4 / 3 /(1+4 / 3), \text { or } 7 / 6>\sqrt{ } 4: \sqrt{ } 3>8 / 7 .
$$

From this, the ratio $28: 17$ is found to be the 'addition' of $\sqrt{ } 2: 1$ and the root guise of $4: 3$, namely $\sqrt{ } 4: \sqrt{ } 3$.

The ratio between the areas of the small central rooms is $12 \frac{1}{4}: 8:: 49: 32$, or $(32+$ $17): 32$. Unlikely as it may have seemed there is this simple family bond between the small rooms and the proportion of the loggia. However, there is more: the 'subtraction' of a

236 LiOnel MARCH - Palladio, Pythagoreanism and Renaissance Mathematics 
convergent to the cube root of 2, 9/7 (for this rational convergent see below) and the square root of $3,7 / 4$, gives

$$
\begin{array}{lc}
9: 7 \text { or } & \sqrt[3]{2}: 1 \\
X & \\
\frac{7: 4}{4} \text { or } & \frac{\sqrt{3}: 1}{\sqrt{3}: \sqrt[3]{2}} \\
49: 36 & |\quad| \\
|\quad| & \underline{3^{2}: 2^{3}} \\
\underline{36: 32} \text { or } 9: 8, & 3^{2 \cdot \sqrt{3}: 2^{3} \cdot \sqrt[3]{2}}
\end{array}
$$

This remarkable symmetrical relation, a rational proxy to $49: 32$, is the product of the square of 3 and its square root to the product of the cube of 2 and its cube root. In the fractional exponent notation introduced in mid-fourteenth century by Archbishop Bradwardine in Tractatus proportionibus [Crosby 1955] and Bishop Oresme in De proportionibus proportionem [Grant 1966]:

$$
3^{2} \cdot 3^{1 / 2}=2^{3} \cdot 2^{1 / 3} .
$$

The skeptic will argue that $\sqrt[3]{2}$ is nowhere to be found in the Antonini set. However a more detailed examination of the tetrastyle hall reveals signs of the Delian cube - the problem of doubling the content of a cube (fig. 7).

32

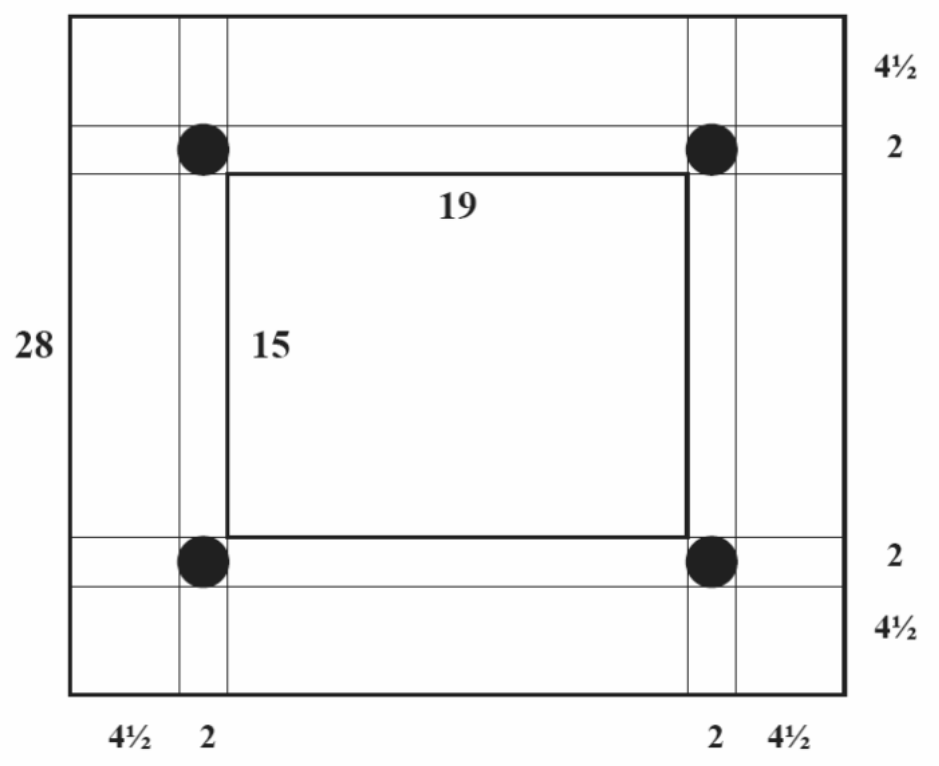

Fig. 7. The arrangement in the tetrastyle hall, Palazzo Antonini 
The space between the four columns is found to be 19 by 15 feet. The ratio $19: 15$ is a good rational proxy for $\sqrt[3]{2}: 1$. The sequence of convergents starts with $4: 3$, which is too large, and the slightly too small $5: 4$, 'petrified' in Vitruvius' pentadoron and tetradoron, two stone blocks the first of which is practically double the volume of the other. Using the Chuquet method [Fowler 1987], $(5+4):(4+3)=9: 7$ is a better value (used in the computation above). This convergent is too large. A better value lies between $5: 4$ and 9: 7 , say $(9+5):(7+4)=14: 11$, though this is still a trifle too large. The next convergent is $(14+5):(11+4)=19: 15$. The cube root of 2 is firmly placed in the most prominent location of the palazzo. It is even found in the internal elevation given that the columns are 19 feet tall (from the elevation) and 15 feet apart in the short direction. In this same direction the distance to the outside of the columns is 19 feet to the distance between of 15 feet. The cube root of two pervades the great hall.

The number 17 evokes the cabalistic tetragrammaton. The Hebrew name of god has the four letters HE VAV HE YOD. These letters have numerical equivalences which were popularized by Agrippa von Nettersheim in De occulta philosophia, 1533. HE = 5, VAV = 6 , and YOD $=1$ so that the four letter name sums to $5+6+5+1=17$. Scholem (1974) describes this method of cabalistic gematria as the "small number" method using only the numbers 1 to 9 . The plan of the palazzo is girdled on three sides by the divine number 17 . The fourth side is marked by the perfect number 28 . These boundary zones are patently auspicious (fig. 8).

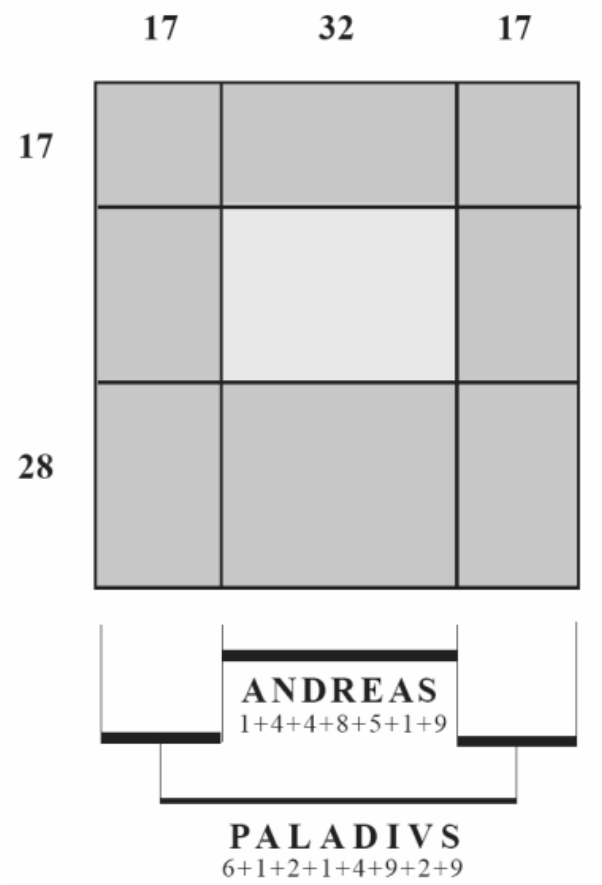

Fig. 8 . The border zones of the plan and the signature of Palladio in the numbers 32 and $17+17=34$ 
Palladio's name was contrived during his time with the humanist Gian Giorgio Trissino, "one of the most illustrious men of our time" [Tavernor and Schofield 1997: 5]. It is an artificial construction. In Latin the name was spelled PALADIVS, or PALLADIVS. It appears on the chapel at Maser with one $\mathrm{L}$, and several documents are signed in this manner. Agrippa provides a nine-chamber arrangement of the 23 letter Latin alphabet (fig. 9). Palladio's Latin names sum to 32 and 34 in the small number method using the digits 1 - 9 only. That is, a number like 60 for $\mathrm{P}$ is reduced to 6 , or 200 for $\mathrm{V}$ to 2 . The double occurrence of the ratio $17: 16$ in the garden loggia may also reflect Palladio's encoded name. The most reduced contemporary encoding of Palladio's name is $3+4=7,3+2=5$. At the very heart of the palazzo is the $50: 49$ room with its familiar echoes of the historic 7 $: 5$ convergent to $\sqrt{ } 2: 1$.

The augmented Antonini set includes the first seven odd primes (fig. 10). Framed by 19 and 3 , the remaining five primes are $17,13,11,7,5$. Is it a mere coincidence that $17.13=$ 221 is the "large" number of ANDREAS, and 11.7.5 = 385 the number of PALADIVS? Remember, these reflect contemporary past-times. Palladio's name was deliberately, intentionally constructed, not given at birth. Barbaro's acknowledgment that Palladio was the Vitruvius of his age is arcanely confirmed in the encoding for VITRVVIVS $=1088=$ $32 \cdot 34=$ ANDREAS PALADIVS.

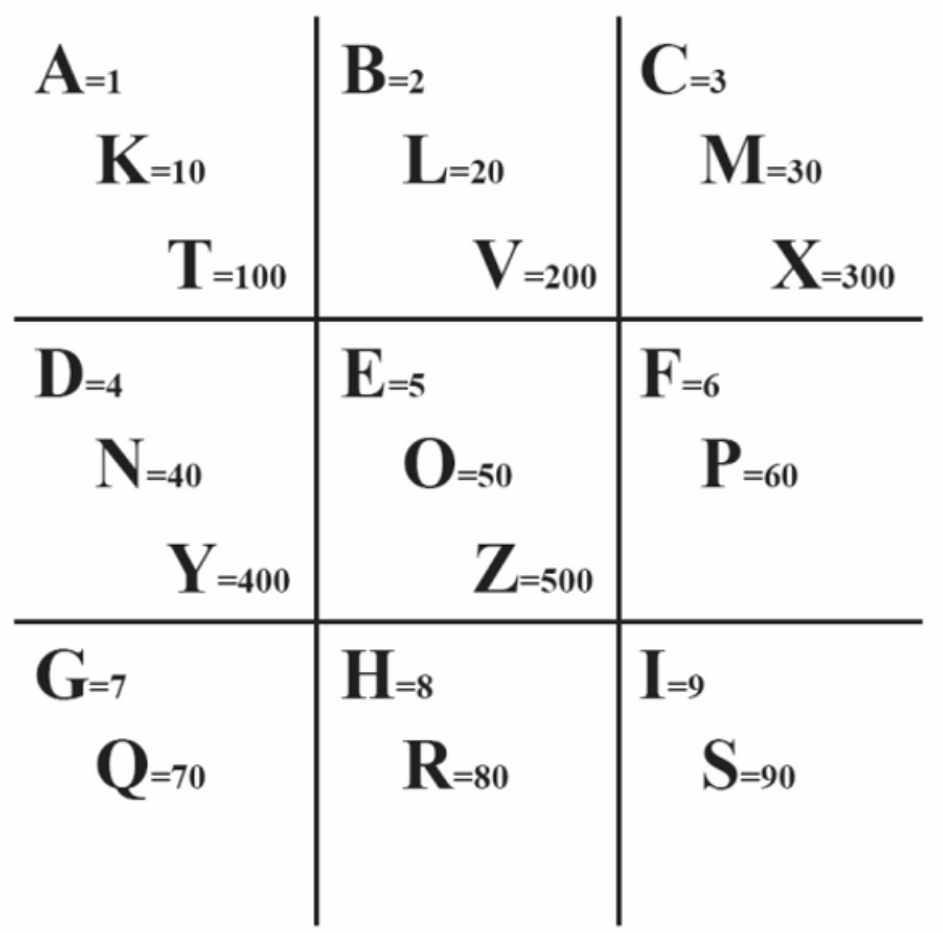

Figure 9. The nine chamber numerical encoding of the Latin alphabet (Agrippa von Nettershaim, 1535) 


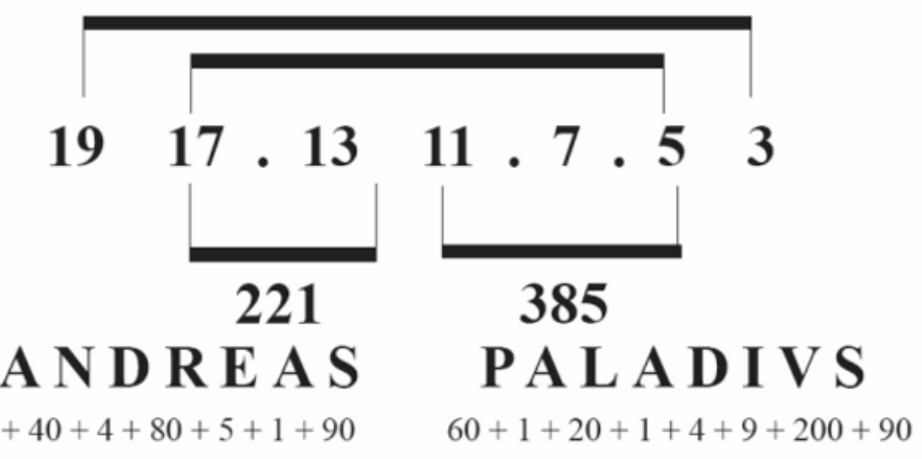

Fig. 10. The encoding of Palladio's Latin name using the full numbers from Agrippa's nine squares

Perhaps, however, there is a simple, practical reason for all of this. In a meticulous and exhaustive study, Mitrović (2004) examines Palladio's buildings and the Quattro libri in the light of previous scholarship. Looking through other palazzo and villa plans, it is certain that powers and rational convergents to roots are discernable throughout. Towards the end of Book II there is a project for Giovanni Battista Garzadori which seems not to conform to the Book I canon or to Alberti's innatae correspondentiae. Principal rooms are proportioned $37: 24,37: 32,37: 40$, and $59: 40$. These dimensions are puzzling until the 37-35-12 Pythagorean triangle is recalled and then all becomes clear. Evident are the dimensions $59=12+35+12$ feet for twice the width of the main hall and $12+20+16=$ 48 feet, four times the short side of the triangle, for the combined length of the side rooms.

Returning to the Palazzo Antonini, the dimensions suggest the 17, 15, 8 triangle for the layout using a marked rope of length $17+15+8=40$ feet. Fig. 11 shows the positions of the 'knots' in the rope if all six possible arrangements of the three side lengths are marked. These 'knots' divide the rope $8+7+2+6+2+7+8=40$. Note that the triple $2+6+2$ reflects the central dimensions of the hexastyle portico: column + intercolumniation + column. The rope is staked out to form a right angle taking the sides of the $17,15,8$ triangle in any order by choosing two appropriate 'knots'.

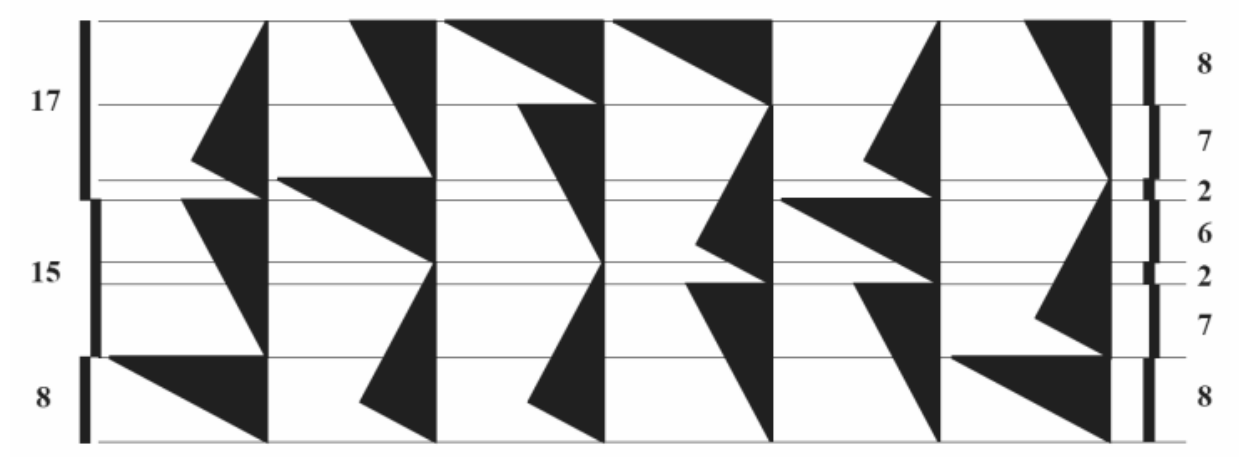

Fig. 11. The six possible arrangements of the 17, 15, 8 Pythagorean triangle to mark a $17+15+8=40$ long rope for surveying purposes 
A reader would have noticed that the woodcut shows the garden-side corner rooms as being rectangular whereas the numbers indicate square rooms, 17 by 17 . If this is a cutter's error, the most likely number to replace 17 is 12 to make a $17: 12$ room (convergent to $\sqrt{2}$ : 1). (Bertotti-Scamozzi's later survey suggests that this is correct). An application of the 17, 15, 8 triangle to laying out the palazzo plan reinforces this supposition (fig. 12). Having set up the triangle in the lower left corner to form a right angle, eight repeated applications of the triangle measure the length of the side wall and parallel cross wall $(8.8=64 \mathrm{feet})$. In the upper left corner of fig. 12, it is shown that the hypotenuse, 17 , can be swung round to measure the location of the cross wall (as well as the outermost columns of the façades). The next cross wall is $17+15=32$ feet away. The procedure of eight applications is repeated to layout the new cross wall and parallel side wall. The front-to-back dimensions of the side rooms, 28, 24, and 12 feet, are clearly marked by the triangulations. The two internal walls parallel to the façade are thus located. The loggia now has the proportion 32 : $12:: 8: 3$, a ratio, double $4: 3$, to be found in rooms at Maser.

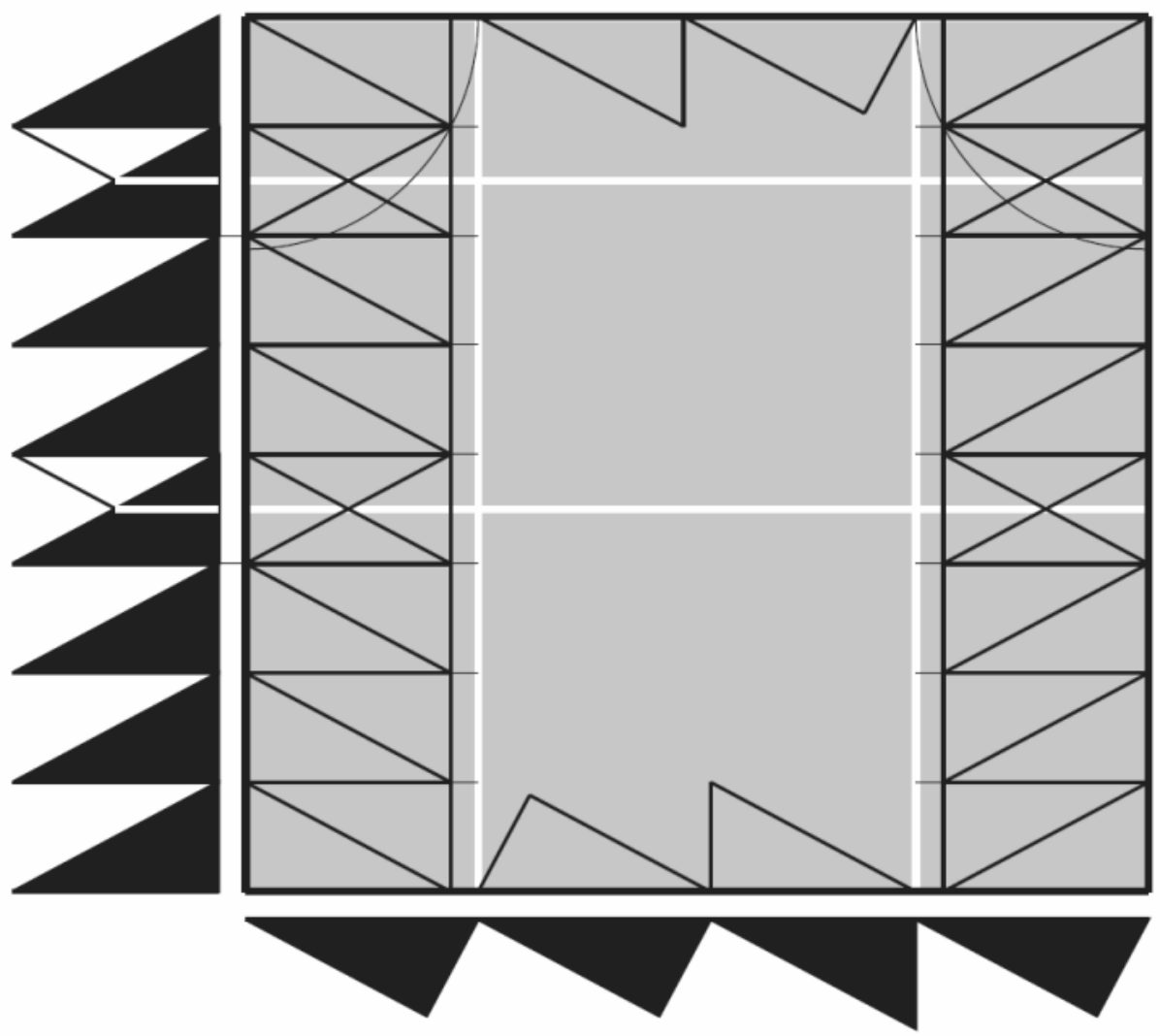

Fig. 12. Laying out the plan of the Palazzo Antonini using a 17, 15, 8 Pythagorean triangle

Next, the three inner rooms are to be marked out. The width of the two small side rooms is 8 feet, the small side of the $17,15,8$ triangle (fig. 13). The length of $12{ }^{1} / 2$ feet is 
easily measured by halving $17+8=25$ feet. Likewise, the width of the central room is measured by dividing $17+15+17=49$ feet in quarter, $12 \frac{1}{4}$ feet. Finally, from the rope, half of $7+2=9$ feet defines the side intercolumniations of the hexastyle portico. All plan dimensions are accounted for using this 17, 15, 8 Pythagorean triangle.

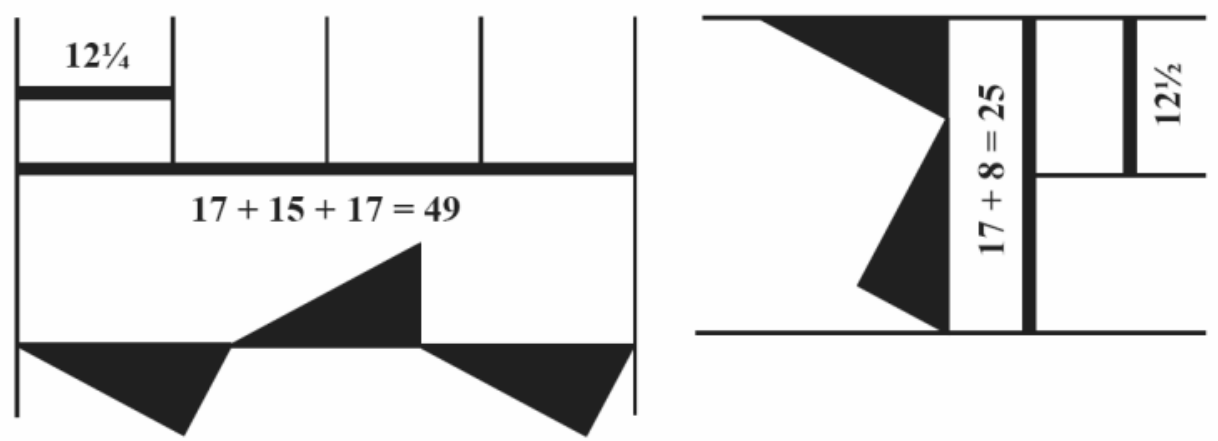

Fig. 13. The 17, 15, 8 Pythagorean triangle is used to set out dimensions of the smaller inner rooms of Palazzo Antonini

Cardano knew of Agrippa's work. Yates [1964] relates that Cardano "despised it as a trivial affair". Cardano was addicted to betting and contributed some of the first studies of probabilities in games of chance. If Cardano had reviewed the Quattro libri, as suggested above, he might well have seen the arithmetical and arcane possibilities indicated above. But just what might these reveal of Palladio's actual mathematical skills? What chance that parts of these readings are serendipitous interpretations separate from the author's intentions? That practical surveying techniques give mundane answers to the enigma? Without doubt, what is certain is that none of these readings are beyond contemporary Renaissance mathematical thought and practices.

\section{References}

Barbaro, D. 1556. Dieci libri dell'archittetura di M. Vitruvio ... . Venice. . 1567. M. Vitruvii Pollionis de architectura libri decem ... . Venice.

CHuQuet, N. 1484. Triparty en la Science des Nombres. Lyon.

Crosby, L. H. 1955. Thomas Bradwardine. Tractatus de proportionibus. Madison: University of Wsconsin Press.

D’Ooge, M. L. 1938. Nicomachus of Gerasa. Introduction to Arithmetic. Ann Arbor. University of Michigan Press.

FlegG, G., C . HAY, and B. MOSS. 1985. Nicolas Chuquet. Renaissance Mathematician. Dordrecht: Reidel.

FOWLER, D. 1999. The Mathematics of Plato's Academy. Oxford: Clarendon Press.

Goodman, M and S. 1983. Johann Reuchlin. On the Art of the Kabbalah. New York: Abaris Books. Grafton, A. 2002. Girolamo Cardano. The Book of My Life. New York: NYRB.

Grant, E. 1966. Nicole Oresme. De proportionibus and Ad pauca respicientes. Madison: University of Wisconsin Press.

HeATH, T. 1986. Euclid. The Thirteen Books of the Elements. New York: Dover.

Herz-Fischler, R. 1998. A Mathematical History of the Golden Number. New York: Dover.

MARCH, L. 1998. Architectonics of Humanism. Chichester, West Sussex: Academy Editions.

Mitrović, B. 2004. Learning from Palladio. New York. W. W. Norton and Company.

Palladio, A. 1570. I quattro libri dell'architettura. Venice. 
RINALDI, R. 1980. Leon Battista Alberti. Ludi matematici. Milan: Guanda.

SCHOLEM, G. 1974. Kabbalah. New York: Dorset Press.

Tavernor, R. and R. Schofield. 1997. Andrea Palladio. The Four Books on Architecture.

Cambridge MA: The MIT Press.

Wassell, S. R. and K. Williams. 2003. Silvio Belli. On Ratio and Proportion. Florence: Kim Williams Books.

Yates, F. 1964. Giordano Bruno and the Hermetic Tradition. London: Routledge \& Kegan Paul.

\section{About the author}

Lionel March, Visiting Scholar, Martin Centre for Architectural and Urban Studies, University of Cambridge. Emeritus Professor of Design and Computation, University of California, Los Angeles. Founding editor, Environment and Planning B. General editor with Leslie Martin, Cambridge Architectural and Urban Studies. Co-author with Philip Steadman, The Geometry of Environment. Author, Architectonics of Humanism, Essays on Number in Architecture. 
